\title{
Práticas discursivas de participação política na internet: uma perspectiva do dissenso
}

Discursive Practices of Political Participation in the Internet: a Perspective of Dissensus

\author{
Petrilson Alan Pinheiro* \\ Universidade Estadual de Campinas \\ Campinas - São Paulo / Brasil
}

Resumo

O objeto deste trabalho é discutir, com base em dados empíricos, como fóruns do Portal da Câmara dos Deputados Federais possibilitam a criação de espaços de movimentos políticos por parte dos usuários do portal. Para entender esses movimentos políticos na internet, fazemos uso dos conceitos teóricos propostos por Rancière de "partage du sensible, "disssensus" e "subjetivação política", que, assim como estabelecem uma relação hierárquica entre aqueles que possuem visibilidade e os que não possuem, dentro de um processo institucionalmente ordenador que aloca indivíduos em lugares particulares, sustentam também o potencial para a sua própria dissolução.

Palavras-chave

Internet; política; dissenso.

\footnotetext{
* petrilsonpinheiro@yahoo.com.br
} 


\section{Abstract}

The objective of this paper is to discuss, based upon empirical data, how forums of the Federal Representatives Website enable users' creation of political movements. To understand such political movements in the internet, we draw from the theoretical concepts, by Rancière, of "partage du sensible", "dissensus" and "political subjectification", which, as well as establishing a hierarchical relationship among those who have visibility and those who do not, inside an institutionally ordering process which allocates individuals in particular places, also sustain a potential for its dissolution.

\section{Keywords}

Internet; politics; dissensus. 


\section{INTRODUÇÃO}

radicionalmente, quando se pensa em participação política popular na esfera pública, o que vem logo à mente é o direito de cada cidadão à escolha, por meio do sufrágio, de seus representantes. Estes, então, seriam os responsáveis por discutir e tomar todas as "decisões políticas" supostamente em nome de seus representados. No entanto, o que essa concepção de participação política expõe, de fato, é uma relação hierárquica de poder, estabelecida através de uma pretensa e organizada ordem que configura as formas de participação em uma comunidade política, que partilha certos tipos de visibilidade para alguns, mas não para outros.

Em oposição a essa concepção de construção das relações políticas, que para Rancière está fundada na ordem da "polícia" e não da política, é que propomos neste trabalho discutir, seguindo a visão do autor, uma concepção alternativa de "política”, que, ao contrário, constitui-se justamente por meio da perturbação e da consequente quebra (dissensão) dos modos legítimos e ilegítimos dessa ordem, abrindo, assim, a possibilidade de uma tomada de partido por aqueles considerados como participantes não legítimos na comunidade política dominante e incentivando, desse modo, a multiplicidade de manifestações na sociedade.

Nesse sentido, consideramos que uma das possibilidades atuais mais interessantes de fazer perceber essa multiplicidade de manifestaçóes é através de diversas práticas discursivas via internet que, após o advento do Web 2.0, em que novos mecanismos vêm sendo criados, estão possibilitando novas condiçôes técnicas e socioculturais, em que as pessoas não apenas recebem, mas também se comunicam entre si e publicam informações na rede.

É com base, portanto, nessa possiblidade de repensar a noção de participação política por meio de práticas discursivas na internet que nos propomos a escrever o presente artigo, cujo objetivo é mostrar como o Portal da Câmara dos Deputados Federais, um ambiente da internet, em princípio, institucionalmente fechado e controlado, possibilita a criação de espaços de 
movimentos políticos por parte dos usuários do portal, que interagem entre si por escrito através de ferramentas digitais como fóruns de discussão, bate-papos e wikis. Para entender esses movimentos políticos na internet, discutiremos, primeiramente, três conceitos teóricos fundantes, propostos por Rancière (1999; 2001; 2004; 2007): "partilha do sensível", "dissenso" e "subjetivação política”. Em seguida, mostraremos como a internet e, mais especificamente, a Web 2.0, possibilita repensar a concepção alternativa de política proposta pelo autor. Para, então, discutir essa relação empiricamente, propomos, como base no construto teórico-analítico dos posicionamentos discursivos, a análise de dois fóruns virtuais no Portal da Câmara dos deputados sobre projetos de lei que contemplam a temática "política sobre as drogas". Por fim, tecemos algumas consideraçōes finais sobre o trabalho como um todo.

\section{RANCIÈRE: POR UMA OUTRA CONCEPÇÃO DE "POLÍTICA"}

Ao discutir a concepção de política, Jacques Rancière desenvolve uma discussão que parte de um de seus conceitos mais fundantes: o de "partilha do sensível" (partage du sensible), que se caracteriza como um:

Sistema de evidências sensíveis que revela, ao mesmo tempo, a existência de um comum e dos recortes que nele definem lugares e partes respectivas. Assim, uma partilha do sensível fixa, ao mesmo tempo, um comum partilhado e partes exclusivas. Essa repartição das partes e dos lugares se funda numa partilha de espaços, tempos e tipos de atividades que determina propriamente a maneira como um comum se presta à participação e como uns e outros tomam parte nessa partilha (RANCIÈRE, 2007, s/p) ${ }^{1}$.

$\mathrm{O}$ autor, assim, parece sinalizar dois sentidos complementares para o termo "partage du sensible": primeiramente, pode se referir às condiçōes de compartilhamento que constituem a coletividade. Nesse caso, o verbo "partager" é entendido como compartilhamento no modo como alguém poderia comunicar informação ou experiência com outra pessoa, um ato de partilha, um princípio de agregação que configura as formas de participação em uma comunidade política; a segunda concepção do termo se refere à interrupção ou dissenso (dissensus) dessa mesma ordem. Nesse caso, "partager" significaria 
separação. Assim, para Rancière, a partage du sensible se constitui a partir de uma tensão, expressa através do conceito de dissensus, que se caracteriza como o dissenso de desigualdade.

Esse duplo conceito do termo partage du sensible (compartilhamento ou divisão), está, assim, relacionado ao(s) modo(s) como uma comunidade partilha certos tipos de visibilidade para alguns, mas não para outros, por meio da delimitação de espaço e tempo, do visível e do invisível, que determina o lugar e os jogos de política como uma forma de experiência. Nesse sentido, a questão primeira e fundamental que se antepóe é a de quem, em um determinado espaço social, é considerado como capaz (habilitado) a fazer uso da palavra. É na origem dessa questão que Rancière estabelece a diferenciação entre a política e a polícia. Segundo o autor (1999, p.8),

A política é geralmente vista como o conjunto dos processos pelos quais se operam a agregação e o consentimento das coletividades, a organização dos poderes, a distribuição dos lugares e funçôes e os sistemas de legitimação dessa distribuição. Proponho dar outro nome a essa distribuição e ao sistema dessas legitimações. Proponho chamá-la de polícia².

Para Rancière, o termo "polícia" refere-se aos cálculos biopolíticos de um poder que reivindica continuamente a noção de política como gestão de abundância e consentimento, gestão essa diretamente relacionada à administração burocrática e ao gerenciamento econômico. Portanto, o autor chama de "polícia" (ordem policial) qualquer ordem social hierárquica - as ordens nas quais todos nós circulamos no nosso cotidiano. A esse respeito, Rancière (1999, p. 29) assevera que:

A polícia é, na sua essência, a lei, geralmente implícita, que define a parcela ou a ausência de parcela das partes. Mas, para definir isso, é preciso antes definir a configuração do sensível na qual se inscrevem umas e outras. A polícia é assim, antes de mais nada, uma ordem dos corpos que define as divisões entre os modos do fazer, os modos de ser e os modos do dizer, que faz com que tais corpos sejam designados por seu nome para tal lugar e tal tarefa; é uma ordem do visível e do dizível que faz com que essa atividade seja visível e outra não o seja, que essa palavra seja entendida como discurso e outra como ruído ${ }^{3}$

Nota-se que a visão alternativa de Rancière se constitui com base na proposição de que a maioria daquilo que é normalmente entendido como 
política deve ser pensado como polícia. Isso inclui as instituições e os processos que governam a organização e a representação das comunidades. Para o autor, a ordem policial atribui posiçóes particulares aos indivíduos na sociedade e toma por certo que o seu modo de se comportar e o de pensar seguem tais posiçōes. Desse modo, a ordem policial supõe que as pessoas têm capacidades distintas e são, por conseguinte, destinadas a ocupar diferentes posições em uma hierarquia. As várias instituições e processos da vida política são pensadas para serem parte desse processo ordenador, que aloca indivíduos em lugares particulares na hierarquia.

Essa hierarquia da ordem social de distribuição (polícia), embora contingente, é fundada em uma base injusta, que trabalha efetivamente como uma espécie de estrutura regulatória na qual a sociedade é um todo do qual todas as partes já são conhecidas - já nomeadas e contadas - e têm de ser meramente organizadas do modo mais harmônico e produtivo. Assim, tal ordem exclui a possibilidade de disputa (dissenso), que, para Rancière, se manifesta quando grupos, indivíduos ou coletividades, cujos modos de percepção são considerados ilegítimos (insensíveis) por uma partição governante do sensível, demandam por serem levados em consideração.

É com base nessa perspectiva que uma partage du sensible, ao mesmo tempo em que estabelece uma relação hierárquica entre aqueles que possuem visibilidade e os que não possuem, dentro de um processo institucionalmente ordenador que aloca indivíduos em lugares particulares, sustenta também o potencial para a sua própria dissolução. Em outras palavras, se a linha de partição é o ponto de contato entre o compartilhamento e a divisão que estruturam a dinâmica de uma partage du sensible, então há sempre a possibilidade de participação política por parte daqueles não institucionalmente autorizados. É nesse sentido de mudança e de dissolução que Rancière (1999, p. 30) constrói a própria noção de atividade política:

A atividade política é a que desloca um corpo do lugar que lhe era designado ou muda a destinação de um lugar. [...] É sempre um modo de manifestação que desfaz as divisões sensíveis da ordem policial ao atualizar uma pressuposição que lhe é heterogênea por princípio, a de uma parcela dos sem-parcela que manifesta ela mesma, em última instância, a pura contingencia da ordem, a igualdade de qualquer ser falante com qualquer outro ser falante. Existe política quando existe um lugar e formas para o encontro entre dois processos heterogêneos ${ }^{4}$.

Com efeito, para o autor, a política ocorre quando certos elementos na sociedade que são considerados não perceptíveis estão desafiando a ordem 
política dominante. A tarefa da ação política, portanto, é estética, uma vez que requer uma reconfiguração das condições de percepção de sentido, de modo que grupos e indivíduos na sociedade possam não apenas existir, mas realmente serem percebidos. Uma partage du sensible é, portanto, uma linha divisória vulnerável que cria as condiçōes perceptivas para uma comunidade política e seus dissensus. Essa linha divisória, para Rancière, estabelece as formas de correspondência e desagregação entre coletividades e é uma unidade básica de análise política que ele aproxima de um ponto de vista estético: com uma sensibilidade para as precondições perceptuais que constroem subjetividades visíveis, audíveis e disponíveis.

Se, como aponta o autor, a ação política requer uma reconfiguração das condições de sentido, por meio do dissenso (dissensus), então este tem a capacidade de interromper os próprios modos como estabelecemos os critérios de conhecimento. Nesse sentido, o dissenso se constitui como um critério perceptual qualificador para participação política. Rancière, portanto, quer desvencilhar a ação política democrática da demanda que corresponde a uma forma de conhecimento autoritário que o legitima. O autor parece, assim, sempre deixar aberta a possibilidade de participação política de todos.

Destarte, a política procura demonstrar que qualquer um poderia, em princípio, ocupar uma posição diferente daquela que, de fato, ocupa e mostrar, por conseguinte, que o trabalho de hierarquização da ordem policial não se baseia em qualquer princípio de ordenação fundacional. Deve-se, contudo, frisar que, para Rancière, a participação política se constitui sempre por meio de uma desordem política na ordem policial, desordem essa fruto de controvérsias e desacordos, na tentativa de reconhecimento da existência política da parte em desvantagem. $\mathrm{O}$ autor chama esse esforço de "subjetivação política" (political subjectification), em que aqueles que não têm a sua parte reconhecida na ordem social, os sans-part, invisíveis ou inaudíveis politicamente falando, reivindicam por sua existência como sujeitos políticos. A esse respeito, Rancière (1999, p.35) aponta que:

A politica é assunto de sujeitos, ou melhor, de modos de subjetivação. Por subjetivação vamos entender a produção, por uma série de atos, de uma instância e de uma capacidade de enunciação que não eram identificáveis num campo de experiência dado, cuja identificação, portanto, caminha a par com a reconfiguração do campo da experiência. [...] A subjetivação política produz um múltiplo que não era dado na constituição policial da comunidade, um múltiplo cuja contagem se põe como contraditória 
com a lógica policial. [...] Um modo de subjetivação não cria sujeitos ex nibilo. Ele os cria transformando identidades definidas na ordem natural da repartição das funções e dos lugares em instâncias de experiências de um litígio 5 .

Assim, o sujeito político seria aquele que, de alguma forma, se opõe, nos termos foucaultianos, às tecnologias de sujeição (ou assujeitamento), que constituem sujeitos assujeitados e silenciados (FOUCAULT,1988), construindo não apenas uma relação de obediência, mas também uma adoção inquestionável pelo indivíduo do discurso do outro, discurso esse que se materializa por meio de uma trama de relações de poder e saber. A subjetivação política, ao contrário, sempre envolve um questionamento do "quem pode fazer o que" na ordem social, por isso nunca se constitui por meio de uma afirmação de identidade (no seu sentido estrito) e sempre envolve um "estar junto", na medida em que estamos sempre no entremeio (entre nomes, identidades, culturas, etc.). Em outras palavras, a subjetivação política envolve uma transformação das identidades dadas, ou seja, trata-se, muito menos, da afirmação de uma determinada identidade (pré-formada), mas da recusa de uma identidade imposta pelos outros, pela ordem policial. Desse modo, a autoafirmação identitária é, para o autor, da ordem da polícia e não da política.

Muito embora Rancière não lide em seus estudos com o ambiente da internet, pensamos que a noção de subjetivação política, baseada no conceito acima discutido de dissensus, pode ser bastante profícua para compreender algumas práticas discursivas de fóruns virtuais de discussão em sites institucionais da internet (como o Portal da Câmara dos Deputados Federais, foco do presente estudo). Isso porque, conforme veremos a posteriori nos dados gerados, a existência (potencial) de espaços de diálogo, no caso do Portal da Câmara dos Deputados Federais, entre representantes políticos (deputados federais) e usuários comuns da internet possibilita não apenas a recusa de uma mera e preexistente identidade de espectador (típica desses portais institucionais) por parte de alguns usuários, mas também a criação de espaços de movimentos políticos, como resultado da própria subjetivação política desses usuários. No entanto, antes de chegarmos aos dados, é preciso refletir sobre uma questão anterior: como a internet possibilita a agência (subjetivação política) por parte dos seus usuários, mesmo em sites institucionais, que, em geral, são rigidamente fechados e controlados (da ordem policial)? Para responder a tal questão, faz-se 
necessário discutir sobre a internet e a Web 2.0, mostrando como esta segunda geração da Web trouxe várias mudanças, sobretudo no que diz respeito à relação produtor/ consumidor.

\section{EM QUE A INTERNET PODE CONTRIBUIR PARA UMA PARTICIPAÇÃO POLÍTICA?}

Lévy (1999) apresenta o ciberespaço como uma grande rede interconectada mundialmente por meio de um processo comunicativo "universal", porém sem "totalidade". Isso segue uma linha de comunicação que vem possibilitando aos navegantes da grande "rede" participar democraticamente de um modelo interativo feito para todos, consolidando, assim, a ideia de uma "aldeia global".

Com efeito, essa participação democrática interativa só passou a se realizar na prática com o advento da Web 2.0. O termo "Web 2.0", usado para designar a segunda fase da rede mundial de computadores, foi usado por O'Reilly (2005) com o intuito de apontar uma série de ferramentas e motivos da internet para entender essas experiências colaborativas como um outro momento da internet. Segundo o autor, a Web 2.0 propiciou uma grande mudança: dos sítios (sites) estáticos da rede, que apenas serviam informação, passou-se para o desenvolvimento de comunidades dinâmicas, inseridas numa interação entre o editor e a audiência.

Para entender melhor o que representa hoje a Web 2.0, é preciso se reportar à geração anterior da web (Web 1.0), fase em que usuários navegavam na internet com o intuito único e exclusivo de procurar informação. Era basicamente uma experiência unilateral, semelhante à ida a uma biblioteca para procurar um livro. Na Web 1.0, os usuários da Internet não eram, portanto, vistos como controladores de seus próprios dados. Aquilo que se obtinha na rede - a informação - era, em geral, fruto do trabalho de profissionais da área que tinham os conhecimentos necessários para criar páginas da web através de programação para publicar na rede. Destarte, a lógica da primeira geração da web era do "uso" e não da "participação"; de "recepção" e "consumo" e não de "interatividade" e "agência".

Diferentemente do que ocorria na Web 1.0, com a consolidação e o acelerado crescimento da internet nos últimos anos, a partir do advento da Web 2.0, novos mecanismos foram sendo criados, possibilitando novas condiçôes técnicas e socioculturais para a ampliação das práticas comunicativas no mundo digital. Nesse novo ambiente, o usuário pode controlar os próprios 
dados. Na nova rede, há, portanto, uma arquitetura de participação que inclui funcionalidades que possibilitam às pessoas não apenas receber, mas também publicar informações no sistema. Assim, mesmo que o usuário não tenha conhecimento técnico, pode criar seus espaços na rede. A exemplo disso, é possível citar o blog, o FaceBook, o Twitter, o Youtube, entre outros suportes digitais, que possuem tecnologias que estimulam os usuários a produzir os seus próprios conteúdos, que, além de possibilitar que as pessoas estejam visíveis na web, também se tornam ambientes em que se formam redes sociais.

Com a Web 2.0, houve, ipso facto, uma reconfiguração no campo da comunicação, tencionando o modelo vigente do broadcast (sistema de transmissão de informação em larga escala), em que apenas um seria responsável pela comunicação. Nessa segunda fase da web, os usuários da internet não apenas pesquisam para encontrar informação; eles também criam e publicam conteúdos, gerando, por conseguinte, uma mudança no modelo de comunicação, que passou do formato "um-para-muitos" para o "muitos-para-muitos". Assim, "as novas tecnologias da informação não são mais simplesmente ferramentas a serem aplicadas, mas processos a serem desenvolvidos. Usuários e criadores podem tornar-se a mesma coisa”. (Castells, 2005, p. 69).

Esse novo modus operandi fez com que a rede passasse a oferecer um novo ambiente, não apenas para leitura, mas para a escrita. Portanto, podemos afirmar que cada tecnologia proporciona um espaço diferente de escrita, acompanhando a evolução dos suportes. O computador disponibiliza seu conteúdo na rede, constituindo-se, assim, como um espaço visualmente complexo e maleável para o escritor e o leitor, gerando fluidez.

Tais (re)configurações criam, de fato, um novo ethos na Web 2.0; um ethos cuja base está no descentramento da noção de autoria e na celebração da "inclusão", na participação em massa do processo produtivo, na distribuição de expertise e na participação e colaboração ativas, constituindo-se como novas práticas de escrita. Isso quer dizer que as práticas que valorizam a participação ao trabalho isolado, o expertise compartilhado ao expertise centralizado, a inteligência coletiva à inteligência individual e a colaboração à autoria individual possibilitam novos letramentos (KNOBEL; LANKSHEAR, 2007).

$\mathrm{O}$ que nos interessa particularmente neste estudo é que esses novos letramentos permitem, entre outras coisas, que qualquer pessoa no ciberespaço possa ser, ao mesmo tempo, produtor, difusor e consumidor de textos, levando 
à inexistência de centros exclusivos de difusão textual, uma vez que qualquer um pode ter hoje o seu espaço na internet e, ao mesmo tempo, entrar e interagir no espaço do(s) outro(s). O ciberespaço, nesse caso, é, antes de tudo, um espaço democrático, que oferece lugar para todos, a todas as culturas e a todas as singularidades (LÉVY, 1999; 2003). Destarte, pode-se dizer que essa possibilidade de atuação direta dos usuários na rede cria novos espaços de atuação na esfera pública. A esse respeito, Lévy (2003, p. 56) assevera que:

A principal vantagem da internet, relativamente aos meios de comunicação da democracia mediática da segunda metade do século XX (imprensa, rádio e televisão), é que permite a todos os agentes se exprimir sem ter de passar pelo poder do jornalista. Resultado: a esfera pública alarga-se, diversifica-se e complica-se particularmente. Esta mutação da esfera pública constitui um dos fundamentos da ciberdemocracia.

Esse alargamento da esfera pública da internet, que gera constantemente espaços de tensões (dissensos), traz em seu bojo uma reconfiguração no que diz respeito ao poder: a de que a internet vem contribuindo para uma reorganização do poder e provocando, segundo Kress (2010), uma mudança das estruturas de poder hierárquicas (verticais) para relações mais abertas e participativas (horizontais). Nesse sentido, a internet pode, de fato, contribuir para a participação política (subjetivação política) de seus usuários, o que vai muito além do modo tradicional de exercer a participação política, que, para a grande maioria das pessoas, se restringe única e exclusivamente à escolha de seus representantes políticos por meio do sufrágio.

Com efeito, podemos ainda questionar o papel político da "representatividade política” em alguns contextos. Por exemplo, se pensarmos no caso do Brasil, especificamente, é possível dizer que a escolha de representantes por meio do sufrágio pode ser, no máximo, considerada uma versão fraca de exercício da política. Isso porque, em um país no qual o voto é obrigatório e os candidatos a representantes políticos, tanto para o poder legislativo quanto para o executivo, em geral, não "representam" sequer a vontade popular, pois, na sua grande maioria, são escolhidos por partidos políticos e apresentados ao povo pela mídia dois meses antes das eleições, a participação "política" popular se restringe a um mero voto - muito mais um dever do que propriamente um direito - para os candidatos no dia das eleições. 
Se formos um pouco além na crítica, talvez fiquemos desolados ao notar que a "representatividade política" no Brasil - e, na verdade, na maior parte das nações mundiais ditas "democráticas" - é composta, ao mesmo tempo, por uma aristocracia - aqui nos atendo à origem grega do termo, como "poder, autoridade, governo dos melhores" - em que, os "melhores" seriam não mais os "nobres", mas aqueles (melhores) escolhidos por partidos políticos, que, somente perto das eleições, são apresentados à população em geral; e composta por oligarquias, pois o poder é exercido por pequenos grupos de pessoas, que, em geral, não representam, de fato, a multiplicidade de espectros sociais e culturais dentro da própria sociedade (classes sociais, etnias, raças, religiōes etc.).

Com base em tal percepção, é possível, então, afirmar que a subjetivação política, nos termos de Rancière, se, de fato, ocorre através do sufrágio, pode ser, no máximo, considerada uma versão fraca, porquanto a partage du sensible, em geral, apenas estabelece uma relação hierárquica entre aqueles que possuem visibilidade e poder (os representantes políticos e aqueles que, de fato, os indicam para ocupar os cargos) e os que não possuem (a grande maioria da população), dentro de um processo institucionalmente ordenador que aloca indivíduos em lugares particulares, não criando, assim, condições perceptivas para o dissensus, que possiblita o surgimento de comunidades políticas.

Em contrapartida, se olharmos para as possibilidades, conforme aponta Lévy (2003), de alargamento, da diversificação e da complicação da esfera pública, por meio da internet, podemos, junto com o autor, vislumbrar, de fato, um caminho possível rumo a uma ciberdemocracia, algo que vai muito além do simples exercício do sufrágio em eleiçōes bienais. Ainda que, em princípio, isso possa parecer utópico, é possível, já na época atual, observarmos alguns ensaios, em escala global, de novos modos de participação (ou subjetivação) política. Dentre esses ensaios, podemos chamar a atenção para dois assuntos que foram divulgados de forma bem ampla na mídia internacional: o primeiro é em relação ao site Wikileaks que, por meio da ação de colaboradores de diversas partes do planeta, desafia superpotências mundiais, sobretudo os Estados Unidos, com suas publicações sobre dados sigilosos governamentais na internet. Tamanha foi a repercussão do site, aliada a uma força ideológica de luta contra poderes hegemônicos globais, que seu principal criador e representante, Julian Assange, chegou até a ser cotado por vários órgãos e autoridades governamentais para o Prêmio Nobel da $\mathrm{Paz}^{6}$. O outro assunto, relacionado ao primeiro, diz respeito 
à famigerada "Primavera Árabe", que se constituiu por meio de manifestações contra diversos ditadores de países árabes do Norte da África e do Oriente Médio, convocadas por meio de redes sociais da internet, que culminaram na saída de vários deles da presidência de seus países, como: Zine El Abidine Ben Ali, da Tunísia, Hosni Mubarak, do Egito, e Muamar Kadafi, da Líbia7.

Em um âmbito mais local, o uso da internet também sinaliza possibilidades bastante interessantes. Uma dessas possibilidades, foco do presente trabalho, é o uso do ambiente online "E-democracia", alocado no Portal da Câmara dos Deputados Federais do Brasil. Como buscamos neste trabalho trazer à tona práticas discursivas de escrita construídas coletivamente por meio do uso de ferramentas típicas da Web 2.0 que visem à participação política de seus usuários, na próxima seção, apresentamos as categorias teórico-analíticas dos posicionamentos discursivos, entendendo-as como elementos analíticos que permitem observar como os participantes, por meio de suas práticas discursivas, (re)constroem significados coletivamente, para então situar essas categorias no ambiente online "E-democracia" por meio de dados empíricos gerados nesse ambiente e mostrar, assim, suas possibilidades de atuação e participação política na esfera pública.

\section{OS POSICIONAMENTOS DISCURSIVOS COMO CATEGORIAS ANALÍTICAS}

Ao trabalhar com os discursos produzidos nos fóruns on-line, estamos entendendo tais discursos como práticas sociais por meio das quais estamos a todo momento (re)construindo significados, e isso é feito com base nas posições que ocupamos nas interações sociais das quais participamos (DAVIES; HARRÉ, 1990), ou seja, com base em determinados posicionamentos ou localizaçóes que tomamos nas práticas discursivas. Esse caráter dinâmico da construção do significado de um evento interacional nos diferentes contextos (sejam eles mais informais ou institucionais) é posto em relevo por alguns autores que abordam a linguagem como um fenômeno social (GOFFMAN, 1981; DAVIES; HARRÉ, 1990; VAN LANGENHOVE; HARRÉ, 1999).

Sob essa perspectiva, cada um de nós, participantes discursivos, está inserido num processo de posicionar a si próprio e aos nossos interlocutores nas práticas discursivas, negociando sempre novas posiçôes. Segundo Van Langenhove e Harré (1999, p. 2), em qualquer "prática discursiva, o 
posicionamento constitui o falante inicial e os outros de uma certa maneira e, ao mesmo tempo, é um recurso por meio do qual todas as pessoas envolvidas podem negociar novas posiçôes (e novos significados)".

O sujeito, portanto e ao se engajar no processo de interação com o outro, age em função de determinadas posições, ao trazer consigo sua visão de mundo, suas experiências de vida, seu modo de agir, etc. Davies e Harré (1997 apud Fabrício: 2002, p. 88) definem o posicionamento como "um termo que faz alusão não só ao conjunto de direitos e obrigações que orientam falantes e ouvintes a agir de determinadas maneiras, mas também à ligação entre as posiçōes por eles assumidas e sua significação como atos sociais". A esse respeito, Davies e Harré (1990, p. 48) ponderam que:

In speaking and acting from a position people are bringing to the particular situation their history as a subjective being, that is the history of one who has been in multiple positions and engaged in different forms of discourse.

Isso significa que os participantes podem, muitas vezes, se posicionar discursivamente com o fito de atingir determinados objetivos em detrimento de outros, de modo a (re)construir suas identidades e as identidades de seus interlocutores. Nesse sentido, o posicionamento pode ser entendido como a construção discursiva de histórias pessoais que "fazem com que as ações das pessoas se tornem inteligíveis e relevantes como atos sociais" (VAN LANGENHOVE; HARRÉ, 1999, p.16).

Os posicionamentos, por conseguinte, são caracterizados por sua natureza dinâmica, em que as inferências dos interlocutores são contextualmente situadas, centradas, uma vez que "as formas concretas que tais posicionamentos vão tomar diferem de acordo com as situaçōes em que ocorrem" (VAN LANGENHOVE; HARRÉ, 1999, p. 30). Desse modo, podemos pensar que, numa mesma interação, por exemplo, um indivíduo pode se posicionar ou posicionar seu(s) interlocutor(es) de diversas maneiras, algumas podendo ser até mesmo contraditórias entre si. Em outras palavras, podemos sempre nos (re)posicionar e (re)posicionar o(s) outro(s) nas práticas discursivas das quais participamos, visto que os posicionamentos são fluidos e provisórios, sempre sujeitos a mudar no decorrer da interação. Esses posicionamentos, portanto, podem também ser 
desafiados, questionados e (re)negociados pelos participantes, o que nos remete às noções de dissenso e subjetivação política a que nos referimos acima.

Van Langenhove e Harré (1999), ao discorrerem acerca do conceito de posicionamento, fornecem um referencial analítico para definir os tipos de posicionamento. Para os autores, o posicionamento pode ser de primeira ou de segunda ordem. No posicionamento de primeira ordem, os indivíduos localizam a si mesmos ou a seus interlocutores discursivamente. Contudo, esse posicionamento pode ser refutado ou questionado pelo(s) interlocutor(es), o que o transforma em um posicionamento de segunda ordem. Este - também chamado de reflexivo-ocorre, portanto, quando um participante discursivo tem seu posicionamento anterior questionado por outro participante e, dessa forma, (re)posiciona-se em favor de seu(s) interlocutor(es) (VAN LANGENHOVE; HARRÉ,1999).

Esses posicionamentos de primeira e segunda ordem podem, segundo Van Langenhove e Harré (1999) ainda apresentar o posicionamento intencional. Segundo os autores, o posicionamento intencional pode ocorrer quando: a) o sujeito deseja mostrar traços de sua identidade, com o objetivo de atingir determinados propósitos específicos (autoposicionamento deliberado); b) a necessidade de assumir determinada posição se dá por exigência do posicionamento de um outro interlocutor (autoposicionamento forçado); c) o sujeito fornece informações sobre outra pessoa (posicionamento deliberado do outro); e d) o sujeito é posicionado por outra pessoa de acordo com os julgamentos de uma dada instituição ou ordem moral (posicionamento forçado do outro) (VAN LANGENHOVE; HARRÉ, 1999, p, 22). Depois de expor as questôes teórico-analíticas que norteiam o presente estudo, passamos, então, na próxima seção, à contextualização e análise dos dados.

\section{PORTAL E-DEMOCRACIA: CONTEXTUALIZAÇÃO E ANÁLISE DOS DADOS:}

O Portal "E-democracia" é um dos ambientes virtuais do site da Câmara dos Deputados Federais do Brasil. Contudo, diferentemente dos demais ambientes do site, o E-democracia se destaca justamente por seu caráter de participação política no que diz respeito à criação de leis no Brasil. Isso vem expresso na própria mensagem de boas-vindas do portal: "Bem-vindo ao Portal e-Democracia! Aqui você pode participar do processo que cria as leis do nosso País". 
No portal, os usuários podem participar das comunidades virtuais que debatem projetos de lei já existentes (em sua fase inicial). Essas formas de participação, que são orientadas conforme o andamento das propostas na Câmara dos deputados federais, constituem-se basicamente de três formas de interação: "bate-papo", "debate" (fórum) e "wikilegis". Em geral, o "batepapo" seria a primeira fase do processo de participação, em que usuários e representantes políticos discutem, em tempo real, sobre um determinado assunto; o "debate", por sua vez, permite uma reflexão maior sobre o assunto discutido, uma vez que é realizado em tempo assíncrono; a "wikilegis" já seria a fase em que se disponibiliza um texto provisório de um projeto de lei a todos os participantes para que eles possam opinar através de sugestôes e comentários.

Cada comunidade online lida com um determinado assunto que pode se transformar em um projeto de lei e ser encaminhado à Câmara dos Deputados. Atualmente, existem no portal vinte e duas comunidades virtuais, das quais nove já se encontram com suas atividades encerradas. Das treze comunidades que ainda se encontram abertas, escolhemos trabalhar com a intitulada "Política sobre Drogas", uma comunidade, segundo o Portal, que tem como objetivo "promover amplo debate com a sociedade para auxiliar os parlamentares na elaboração de uma política pública sobre drogas" ${ }^{\prime \prime}$. Devido às limitações deste artigo, de todo o corpus gerado para este estudo, analisaremos aqui apenas a atividade de "debate", não contemplando, assim, as atividades de "bate-papo" e "wikilegis". A opção pela escolha da atividade de debate se deu em função de esta ser uma fase em que os usuários participantes se identificam (inclusive com fotos) e procuram manter uma regularidade na sequência de ideias que cada um apresenta, porquanto a atividade se constitui de forma assíncrona, permtindo-nos, assim, uma análise mais acurada e em consonância com a proposta teórica apresentada neste estudo.

Dentro da comunidade on-line "Política sobre Drogas", na atividade de "debate", foram levantados diferentes fóruns relacionados ao tema. Cada fórum recebe um título e, embora o número de usuários que participam com algum comentário seja relativamente pequeno, o número de visualizações - pessoas que visitam os fóruns pode ser considerado bastante extenso. Entre os fóruns que estavam abertos dentro da comunidade "política sobre drogas" no período de janeiro a junho de 2012, escolhemos dois: "Dep. Iracema Portella sobre o Fundo Nacional Antidrogas (FUNAD)", aberto pela própria deputada Iracema Portella, e "Conheça e colabore com o relatório preliminar: faça comentários sobre o relatório preliminar”, aberto pela Equipe do E-democracia ${ }^{11}$. 
10 Fórum: "Dep. Iracema Portella sobre o Fundo Nacional Antidrogas (FUNAD)"12

\begin{tabular}{|l|l|}
\hline Dep. Iracema Portella & $\begin{array}{l}\text { Dep. Iracema Portella fala sobre o Fundo Nacional } \\
\text { Antidrogas (FUNAD) } \\
\text { A deputada Iracema Portella fala sobre o PL 1359/2011, de } \\
\text { sua autoria, que define critérios para a diretrizes para doação } \\
\text { ao Fundo Nacional Antidrogas (FUNAD) e utilização dos } \\
\text { recursos. }\end{array}$ \\
\hline $\mathbf{1 0}^{\mathbf{0}}$ participante & $\begin{array}{l}\text { RE: Dep. Iracema Portella fala sobre o Fundo } \\
\text { Nacional Antidrogas }\end{array}$ \\
& $\begin{array}{l}\text { (FUNAD)CHEGA DE PAGARMOS IMPOSTOS. O } \\
\text { CUSTO DE VIDA NO BRASIL JA ESTÁ MUITO } \\
\text { CARO } \\
\text { A MELHOR MANEIRA DE ARRUMAR VERBAS } \\
\text { PARA RECUPERAÇÃO } \\
\text { É SOBRETAXAR O CIGARRO O ALCOOL } \\
\text { LIBERAR A MACONHA } \\
\text { PARA PLANTIO, MEDICINAL, RECREATIVO E } \\
\text { INDUSTRIAL } \\
\text { OS PLANTADORES SERÃO CADASTRADOS, } \\
\text { PARA CULTIVO DOMÉSTICO/INDUSTRIAL } \\
\text { SERIA FEITO MEDIANTE UM CADASTRO, E } \\
\text { AS PESSOAS PAGAREM UM IMPOSTO SOBRE } \\
\text { A PLANTAÇÃO POR MES, A UMA QUANTIA } \\
\text { MÍNIMA... TODO O IMPOSTO SERIA } \\
\text { REVERTIDOS PARA TRATAMENTO } \\
\text { NÃO SERIA JUSTO COBRAR IMPOSTOS DE } \\
\text { PESSOAS QUE NÃO UTILIZAM. } \\
\text { SOBRETAXAR O IMPOSTO DE IMPORTADORAS, } \\
\text { INDUSTRIAS DE CIGARRO, ALCOOL. } \\
\text { SÓ PAGA QUEM CONSOME, E QUEM FORNECE. }\end{array}$ \\
\hline
\end{tabular}




\begin{tabular}{|l|l|}
\hline Dep. Iracema Portella & $\begin{array}{l}\text { Eu também acho, Xxxxx, que a carga tributária no Brasil } \\
\text { é alta demais. Gostaria apenas de esclarecer um ponto } \\
\text { importante do meu projeto sobre o Fundo Nacional } \\
\text { Antidrogas. Nossa proposta não cria nenhum imposto nem } \\
\text { aumenta a carga tributária. O que o projeto prevê é que } \\
\text { as pessoas, físicas ou jurídicas, tenham a oportunidade de } \\
\text { reservar parte do imposto que elas já pagam, ou seja, que } \\
\text { já é recolhido pela Receita Federal, para o financiamento } \\
\text { das políticas públicas de combate às drogas. É uma maneira } \\
\text { de envolver os brasileiros nessa luta, fortalecendo a nossa } \\
\text { democracia e o exercício da cidadania. }\end{array}$ \\
& $\begin{array}{l}\text { Muito obrigada pelos seus comentários, } \\
\text { Atenciosamente, } \\
\text { Iracema Portella }\end{array}$ \\
\hline
\end{tabular}

\begin{tabular}{|l|l|}
\hline $2^{\mathbf{0}}$ participante & $\begin{array}{l}\text { Creio que não seja esse o primeiro passo a darmos em uma } \\
\text { situação de extrema delicadeza como essa. Primeiramente } \\
\text { gostaria de parabenizar a Dep. pela ideia, que apesar de } \\
\text { precoce me parece muito agradável. Porém, creio que por } \\
\text { culpa da legislação e do atual tratamento prestado aos } \\
\text { dependentes químicos esse seria apenas mais um dinheiro } \\
\text { do povo gasto com impostos que, na prática, não tem } \\
\text { finalidade ou retorno notável. }\end{array}$ \\
\hline $\mathbf{3}^{\mathbf{0}}$ participante & $\begin{array}{l}\text { Seria eficiente se conseguissem fazer essa verba chegar } \\
\text { até a saúde e educação, e não destina-la para o pomposo } \\
\text { "Combate as Drogas". Elas não devem ser combatidas, e } \\
\text { sim a falta de saúde e educação.Logo, critico até mesmo } \\
\text { a existência de uma secretaria "anti drogas", muito mais } \\
\text { um "fundo anti drogas". Pois isso é uma das principais } \\
\text { engrenagens da corrupção. }\end{array}$ \\
\hline
\end{tabular}




\begin{tabular}{|c|c|}
\hline $4^{\circ}$ participante & $\begin{array}{l}\text { Por que drogas afinal ? Nosso país é um país miseravel, } \\
\text { afinal de contas essa riqueza em que o governo adora } \\
\text { divulgar, crescimento de } 8 \% \text { ao ano, e afinal, onde foi parar } \\
\text { realmente essa riqueza? aposto que nas mãos de muitos } \\
\text { poucos, sériam as drogas um problema social? Sim, eu } \\
\text { acredito nisso. } \\
\text { Tente olhar o que leva um viciado de crack a usar crack, } \\
\text { você vive em um lugar pobre, sem educação, saneamento, } \\
\text { sem cultura alguma, sem nada daquilo que consideramos } \\
\text { essencial para uma bom desenvolvimento intelectual e } \\
\text { espiritual. } \\
\text { Pense, todos os dias você acorda e ver que não há } \\
\text { pespectiva para você, que não há emprego, pois você não } \\
\text { tem conhecimento, e mesmo sem conhecimento, os } \\
\text { obstaculos para se obter algo assim não extratosfericos. Para } \\
\text { que afinal se investir em planos de combate a drogas e se o } \\
\text { verdadeiro vilão anda a solta, por que não usar o dinheiro } \\
\text { e investir em educação? } \\
\text { Educação meus caros é a base de tudo, duvido muito que } \\
\text { uma pessoa que recebeu uma educação de qualidade venha } \\
\text { a ter necessidade de usar crack ou oxi, ela vai ter condições } \\
\text { de arrumar um emprego, de ter uma vida social comum, } \\
\text { talvez fume maconha, mas, como se sabe, aqueles que } \\
\text { viciam é quem tem em grande parte problemas emocionais } \\
\text { na bagagem da vida. Então eu lhes pergunto? Vamos ficar } \\
\text { criando planos, e bolsas contra a droga, ou vamos acorda para } \\
\text { o mundo e fazer realmente o que interessa e é mais urgente? }\end{array}$ \\
\hline Dep. Iracema Portella & $\begin{array}{l}\text { Obrigada, Xxxxx. O que estamos tentando é justamente } \\
\text { melhorar a legislação sobre o tema das drogas e as políticas } \\
\text { públicas de prevenção, tratamento, reinserção social e repressão } \\
\text { ao tráfico. É preciso que todos façam um grande esforço no } \\
\text { sentido de enfrentar, com muita determinação e vontade } \\
\text { política, essa luta. Nosso projeto, como já expliquei, não prevê } \\
\text { nenhum imposto a mais. É apenas mais um mecanismo para } \\
\text { melhorar o financiamento das políticas públicas de combate } \\
\text { às drogas. É bom que a sociedade participe ativamente desse } \\
\text { processo. } \\
\text { Atenciosamente, } \\
\text { Iracema Portella }\end{array}$ \\
\hline
\end{tabular}




\begin{tabular}{|c|c|}
\hline Dep. Iracema Portella & $\begin{array}{l}\text { Caro Xxxxx, } \\
\text { Você está certo. Educação é a base de tudo. Precisamos } \\
\text { oferecer às nossas crianças e jovens oportunidades concretas } \\
\text { para que possam se desenvolver plenamente. Precisamos } \\
\text { de educação de qualidade, saúde de qualidade, moradia de } \\
\text { qualidade, esporte, cultura e lazer para a garotada. Tudo isso } \\
\text { é prevenção, tudo isso é capaz de colocar nossos meninos } \\
\text { e meninas longe das drogas. Mas é fundamental também } \\
\text { recuperar quem já entrou nesse mundo. É preciso melhorar } \\
\text { as políticas públicas de tratamento dos usuários, reinserção } \\
\text { social e requalificação profissional desses dependentes } \\
\text { químicos. É preciso também implementar estratégias de } \\
\text { repressão ao tráfico de drogas. São todas açóes importantes } \\
\text { que devem ser adotadas em perfeita sintonia. } \\
\text { Atenciosamente, } \\
\text { Iracema Portella }\end{array}$ \\
\hline $2^{\circ}$ participante & $\begin{array}{l}\text { Cara Dep. Iracema,Você está certa quando cita que } \\
\text { repressão ao tráfico e reinserção social sejam os caminhos } \\
\text { corretos, porém ainda afirmo que o primeiro passo para tal, } \\
\text { seja a descriminalização da maconha, que ao meu ver é a } \\
\text { vítima nessa historia toda, abrindo porta para adolescentes } \\
\text { conhecerem novas drogas, já que a "inocente" erva só pode } \\
\text { ser adquirida através do tráfico na atualidade. }\end{array}$ \\
\hline $5^{\circ}$ participante & $\begin{array}{l}\text { Deputada, repressao ao trafico nao funciona. Em lugar } \\
\text { algum do mundo. Nao vai ser aqui que vai funcionar. O } \\
\text { correto seria seguirmos o exemplo da Argentina. Com o } \\
\text { cultivo caseiro da maconha (que responde por } 80 \% \text { da } \\
\text { renda dos traficantes) liberado, nao de direito mas sim na } \\
\text { pratica, os traficantes vao falindo a medida que as pessoas } \\
\text { aprendem a plantar. Pense nisso, nem so com dinheiro se } \\
\text { resolvem problemas. }\end{array}$ \\
\hline
\end{tabular}




\section{$6^{\circ}$ participante}

Entendo a importância do projeto. Realmente uma forma interessante de conseguir fundos para projetos específicos.

Mas já que é para reduzir o problema das drogas nem um centavo desse dinheiro deveria ser usado na repressão. Como bem disse o Xxxxxx e eu a senhora concordamos: Educação é a base de tudo.

Então, concordo plenamente com o projeto no sentido de criar uma excelente fonte de recursos, que não aumenta a carga tributária mas basicamente deixa o cidadão decidir que uma fração de seus impostos seja usada MESMO no projeto que apoia. Mas queria entender como seriam usados esses recursos. Qual é o plano? Qual é a métrica e qual é o objetivo?

Eu acredito que o destino deva ser totalmente dedicado a pesquisa cientifica das drogas, inclusive possibilidades medicinais, do perfil de seus usuários e por fim na educação honesta e livre de mitos sobre drogas.

Qualquer termo "repressão" nos objetivos dessa proposta me afasta dela, em resumo.

ps.:Regulamentar a maconha medicinal, junto a Anvisa (que pode mudar a planta na sua lista, nem precisa mudar a lei de drogas), estabelecer regras para os dispensários cooperativos sem fins lucrativos mas com impostos para projetos de educação e prevenção de drogas seria uma fonte de renda muito, muito mais promissora. Nem precisa mudar a lei atual, um dedo do executivo na lista da Anvisa, criação de normas para pesquisas nas universidades e posteriormente para os estabelecimentos de cultivo e venda - pronto. 


\section{$4^{\circ}$ participante}

Cara deputada, combater o tráfico, se não é possivel combater dentro da prisão, imagine no mundo fora dela. Esse combate está perdido, é inutil, nem mesmo os EUA que são a maior potencia militar do planeta conseguiram, e logo aqui, no Brasil, onde os policiais são corruptos devido a não legalização claro, e onde há cidades em que o delegado deixa a prisão na mão do preso pra ir tomar um café. Sejamos francos, repressão nunca deu certo e nem vai dar. Muito mais inteligente legalizar e trabalhar em cima disso.

De início, é interessante notar que o fórum apresenta uma estrutura que possibilita aos participantes não apenas se identificar (exibir nome e foto, por exemplo), como também escrever seus comentários sem um limite de espaço determinado e voltar a escrever quantas vezes quiserem (alguns participantes voltam a postar comentários para complementar algo que disseram anteriormente ou para comentar o que outros participantes postam).

O fórum é aberto com a postagem da deputada Iracema Portella, que assumi um posicionamento de primeira ordem (c.f.: Van Langenhove \& harré:1999) para apresentar o projeto de lei de sua autoria com o intuito de definir os critérios e diretrizes para doação e utilização dos recursos destinados ao "Fundo Nacional Antidrogas" (FUNAD). Por procurar não apenas saber o que os participantes do fórum pensam a respeito do projeto, mas também mostrar suas visões sobre o assunto, disponibilizando, inclusive, um link de um vídeo em que ela fala sobre a criação do FUNAD, a deputada também assumi um autoposicionamento deliberado, um posicionamento intencional, segundo Van Langenhove \& Harré (c.f.: 1999), em que o sujeito tem como objetivo atingir determinados propósitos específicos; no caso específico do fórum, o de tentar convencer os demais participantes da importância e da necessidade premente da criação do FUNAD.

A partir, então, do posionamento da deputada, começa, então, haver uma certa insatisfação coletiva dos participantes, que se mostram, em geral, contrários à criação do Fundo. O primeiro participante já começa seu comentário discordando da ideia da criação do FUNAD, pois considera que aumentar a carga tributária daqueles que não fazem uso de drogas não seria justo. Para ele, o que se deveria fazer é sobretaxar outras drogas, como cigarro e álcool, e deixar de lado a maconha. O segundo participante, alinhando-se ao primeiro, pondera 
que essa medida seria "mais um dinheiro do povo gasto com impostos que, na prática, não tem finalidade ou retorno notável”.

Nesses casos, observa-se que os participantes assumem posicionamentos de segunda ordem (c.f.:Van Langenhove \& Harré:1999), por meio de autoposicionamentos deliberados, posicionamentos reflexivos que se constituem através do questionamento da Deputada em relação à importância da criação do FUNAD.

Apesar de concordar com o primeiro participante que a carga tributária no Brasil é muito alta, assumindo assim um autoposicionamento forçado - a necessidade de assumir determinada posição por exigência do posicionamento dos dois primeiros participantes - a deputada Iracema Portella assume também um posicionamento de segunda ordem, um autoposicionamento deliberado, na tentativa de convencer os dois participantes que de tal Fundo não criaria um imposto a mais, mas apenas um "mecanismo para melhorar o financiamento de políticas públicas de comate às drogas".

O primeiro partipante, então, novamente assume um autoposicionamento deliberado ao trazer um comentário para reforçar sua ideia de descriminalização da maconha, porém não recebe resposta da deputada.

O terceiro participante se posiciona então de duas formas: a primeira é de segunda ordem, que se constitue por meio do posicionamento deliberado do outro, ao concordar com o primeiro participante que a carga tributária no Brasil é muito alta, e a segunda, de primeira ordem, ao defender que a verba que seria utilizada pelo FUNAD deveria ser usada na saúde e na educação, criticando, assim, a própria existência do fundo.

O quarto participante, do mesmo modo, assume então dois posicionamentos: o primeiro é um de segunda ordem, que se constitue por meio do posicionamento deliberado do outro, ao concordar com o terceito participante, que chama a atenção para a educação, ao mesmo tempo em que critica o investimento no que chama de "planos de combate às drogas" (autoposicionamento deliberado).

A deputada, então, embora concorde com ele de que a educação é fundamental e pode ser, de fato, o melhor modo de prevenção (autoposicionamento forçado), assume, no entanto, um autoposicionamento deliberado de primeira ordem, para argumentar em defesa do FUNAD, chamando a atenção para as pessoas que já são usuários de drogas e que precisam de tratamento, reinserção social e qualificação profissional. Além disso, ela ainda defende que o Fundo possa colaborar na repressão ao tráfico de drogas. 
O sexto participante, então, assume um posicionamento autodeliberado de segunda ordem ao discordar da deputada quanto à repressão ao tráfico, já que, para ele, isso não funcionaria. $\mathrm{Na}$ esteira do mesmo argumento, novamente o quinto participante, apesar de reconhecer a importância do projeto, assume dois posicionamentos: um autoposicionamento deliberado, ao criticar a repressão ao tráfico, e um posicionamento deliberado do outro, ao concordar com terceiro participante (que se deve investir em educação). Questiona ainda o modo como seriam usados os recursos do FUNAD, que, para ele, não está claro.

Por fim, o quarto participante volta com mais um comentário, reproduzindo, primeiramente, a resposta que havia recebido da deputada (colando no início do seu comentário), o que se caracteriza por um posicionamento deliberado do outro, para, então, ressaltar, assim como os demais particiapantes, que o combate ao tráfico é algo inútil. Os dois últimos comentários não tiveram resposta da deputada.

É possível observar na interação realizada entre os participantes envolvidos que, mesmo tendo sido criado por uma parlamentar (a Deputada Iracema Portella), o fórum possibilita, de fato, dar voz aos usuários participantes. Isso porque, ainda que saibamos que o fórum é institucionalmente controlado, e que, por isso, certos comentários de usuários poderiam ser excluídos, podemos, por outro lado, notar que o fórum permite a reverberação de vozes dissonantes (posicionamentos deliberados) que não estejam de acordo com as próprias propostas institucionais em questão. A esse respeito, nota-se, por exemplo, que o Projeto de Lei sobre a criação do FUNAD que pretende destinar recursos financeiros ao combate do tráfico de drogas, embora seja institucionalmente defendido pela Deputada que o criou, é rechaçado pelos participantes do fórum, que não apenas criticam a proposta, como também trazem outras alternativas para o uso dos recursos públicos. Dando sequência à análise dos dados, exibimos abaixo a discussão no fórum "Conheça e colabore com o relatório preliminar: faça comentários sobre o relatório preliminar", aberta pela Equipe do E-democracia. 


\section{$2^{\circ}$ Fórum - 08/12/2011 - Faça comentários sobre o relatório preliminar}

Equipe e-democracia

Estoris
Especial de Política sobre Drogas da Câmara dos Deputados. $\mathrm{O}$ relator que saber a sua opiniāo sobre o relatório ${ }^{13}$. Conheça o relatório e contribua com comentários neste Tópico!Equipe e-Democracia

\begin{tabular}{|l|l|}
\hline $2^{\circ}$ participante & $\begin{array}{l}\text { Bom não tenho criticas a fazer, achei bastante lucido o } \\
\text { relatatório, sem visōes preconceituosas como vemos as veses.A } \\
\text { questão das drogas é realmente complexa um grave problema } \\
\text { q temos neste país é o preconceito e até raiva as veses por } \\
\text { parte da policia e da sociedade com relação ao usuario, o } \\
\text { q resulta em abordagens geralmente violentas por parte da } \\
\text { policia q abordam os usuarios como se fossem bandidos } \\
\text { perigosos apontando armas, batem xingam humilham , e } \\
\text { isso é motivado por preconceito. A sociedade em geral trata } \\
\text { o usuario como retardado e bode espiatorio de todos os } \\
\text { problemas, a midia ajudou bastante a criar essa mentalidade } \\
\text { esses anos todos. } \\
\text { É NECESSARIO PREPARO DA POLICIA E DO } \\
\text { JUDICIARIO PARA SABER LIDAR COM OS USUARIOS } \\
\text { SEM SE BASEAR EM SUPOSIÇÕES E PRECONCEITO } \\
\text { COMO ACONTECEU NO CASO DO SATIVALOVER. } \\
\text { (usuario acusado de trafico sem prova alguma e q continua } \\
\text { preço até o presente monento) } \\
\text { milhões de consumidores de cerveja não tem o direito de } \\
\text { falar mal da maconha é tudo a mesma coisa. Alias o alcool e } \\
\text { cigarro são muito piores e as pessoas podem fase-lo sem serem } \\
\text { discriminadas os maconheiros tem q ter o mesmo direito. } \\
\text { Ou seja respeito por parte da sociedade e das autoridas e } \\
\text { acesso a produto de qualidade sem correr riscos desnecessários } \\
\text { gerados pela proibição. Prioridade acabar com a violencia } \\
\text { gerada pela proibição e desrespeito aos dirteitos individuais } \\
\text { de escolha. } \\
\text { Tenho dito. E Q o pai eterno continue abençõando nossa } \\
\text { breve passagem por esse mundo. }\end{array}$ \\
\hline
\end{tabular}




\begin{tabular}{|c|c|}
\hline Equipe e-democracia & $\begin{array}{l}\text { Relatório preliminar apresentado pelo relator da Comissão } \\
\text { Especial de Política sobre Drogas da Câmara dos Deputados. } \\
\text { O relator que saber a sua opinião sobre o relatório }{ }^{13} \text {. Conheça } \\
\text { o relatório e contribua com comentários neste Tópico!Equipe } \\
\text { e-Democracia }\end{array}$ \\
\hline $3^{\circ}$ participante & $\begin{array}{l}\text { Não discordo de quase nada dito em relação a prevenção, } \\
\text { acolhimento e reinserção social. Porém, ao se tratar da } \\
\text { maconha, assunto de mera importância na atual legislação, } \\
\text { fui decepcionado! } \\
\text { Gostaria de saber como uma comissão pode se basear em uma } \\
\text { informação que "parece ser" verídica ao alertar que "o uso da } \\
\text { maconha não deve ser considerado um problema menor". } \\
\text { Comparado ao crack?! } \\
\text { Com certeza é um problema muito menor, que se devidamente } \\
\text { resolvido, resultaria na diminuição do numero de pessoas que } \\
\text { se relacionam com o tráfico, consequentemente gerando } \\
\text { prejuízo econômico ao crime organizado, apenas com o ato } \\
\text { de plantar a sua planta de cannabis dentro de casa. } \\
\text { O assunto não pode ser deixado de lado por essa Comissão, } \\
\text { entendo a importância da prevenção ao crack, mas com } \\
\text { certeza muitos usuários iniciais de cannabis nem se quer } \\
\text { sabiam como se usava uma pedra de crack na primeira vez em } \\
\text { que foram comprar sua trouxa de maconha! As tais "pesquisas } \\
\text { recentes" devem no mínimo ser apresentadas pela Comissão. } \\
\text { Como citado no relatório, essa é uma das não raras vezes, em } \\
\text { que a informação carece de amparo científico. } \\
\text { e como tem dito o Xxxxx, que o pai eterno continue } \\
\text { abençôando nossa breve passagem por esse mundo. }\end{array}$ \\
\hline $4^{\circ}$ participante & $\begin{array}{l}\text { Porque não houve nenhuma menção, ou pelo menos } \\
\text { indicação do que foi debatido aqui? } \\
\text { No RELATORIO, na pagina } 74 \text {, não foi apontado } \\
\text { nenhuma conclusao dos trabalhos realizados no ambito do } \\
\text { E-Democracia. } \\
\text { Como fica? } \\
\text { abs }\end{array}$ \\
\hline
\end{tabular}




\section{$5^{\circ}$ participante}

Adorei a piada, mas já passou a graça, agora mostrem o relatório de verdade vai... sem brincadeira... cadê?

Este segundo fórum é iniciado pela Equipe do e-democracia, que assume um posicionamento autodeliberado de primeira ordem ao solicitar aos participantes que opinem sobre o relatório "Propostas para políticas públicas sobre drogas no Brasil", que é disponibilizado por meio de um link ${ }^{13}$. Os participantes do fórum, então, começam a manifestar suas opiniões a respeito do relatório.

O primeiro participante assume um posicionamento autodeliberado de segunda ordem, ao apontar o fato de a maconha, principal tema da enquete sugerida pelo próprio relator da proposta, não ter sido devidamente tratado no relatório. Ele, então, propõe que se discuta sobre a regulamentação da maconha para fins medicinais.

Fazendo também uma crítica em relação ao modo como a questão maconha é tematizada no relatório, o segundo participante constrói seu comentário, primeiramente, assumindo um posicionamento deliberado do outro, ao trazer um citação retirada da internet e um trecho destacado do próprio relatório para, então, assumir um posicionamento autodeliberado de segunda ordem, ao afirmar que, apesar de não "discordar de quase nada dito em relação à prevenção, acolhimento e reinserção social”, ao se tratar da maconha, ele se diz decepcionado, pois, segundo ele, algumas informações que constam no relatório "carecem de um amparo científico".

O terceiro participante, do mesmo modo, assume um autoposicionamento deliberado de segunda ordem ao fazer uma crítica em relação ao fato de não ter havido nenhuma menção ao que se vinha discutindo até então nos fóruns do E-democracia no relatório. Por fim, parecendo seguir a mesma crítica, porém em um tom jocoso, o quarto participante, assumindo também um autoposicionamento deliberado de segunda ordem, pergunta a respeito do relatório que, por não contemplar as discussões dos participantes, sequer parece ser, segundo ele, o relatório "de verdade". Diferentemente do primeiro fórum mostrado, não houve respostas por parte do criador e/ou moderador deste segundo fórum, uma vez que as discussões se restrigiram aos usuários participantes.

Com efeito, podemos dizer que os fóruns em questão, por serem institucionalmente controlados, pertencem, para Rancière, à ordem da "polícia". 
Nesse sentido, observa-se, por exemplo, que a Deputada Federal Iracema Portella (no primeiro fórum) e a Equipe e-democracia (no segundo fórum) são aqueles que representam essa ordem institucional, uma vez que são eles que têm o poder de permitir os comentários que podem ou não permanecer no fórum, bem como os comentários que desejam ou não responder.

Contudo, podemos dizer que essa mesma linha divisória - aqui entendendo-a como uma partage du sensible - que cria uma divisão entre os que são e os que não são institucionalmente autorizados, também cria as condições perceptivas para o seu dissenso. Em outras palavras se, para Rancière (2004, p. 32) "a política é uma atividade que não apenas interrompe a ordem policial, mas a reconfigura para melhor" ${ }^{14}$, então, qualquer ação política requer, de fato, uma reconfiguração das condições de sentido, por meio do dissenso, pois este tem a capacidade de interromper os próprios modos como se pode estabelecer a participação política e de trazer contribuiçôes para seu aprimoramento.

De fato, essa participação política que, para Rancière, é uma unidade básica de análise política que se aproxima de um ponto de vista estético - uma sensibilidade para as precondiçōes perceptuais que constroem subjetividades visíveis, audíveis e disponíveis - parece se estabelecer por meio dos fóruns no momento em que se percebe que a oposição entre os "experts" (os deputados federais) e as pessoas comuns (os participantes do fórum) é substituída por argumentos sociotécnicos que articulam diferentes tipos de considerações por meio de seus posicionamentos discursivos. O conflito não é extinto, mas modificado. Nesse caso, a controvérsia - em relação à descriminação e à legalização da maconha, por exemplo - permite a redefinição de projetos e soluções que integrem a pluralidade de pontos de vistas, demandas e expectativas.

Podemos, desse modo, afirmar que a controvérsia dos participantes dos fóruns em relação a certos pontos estabelecidos nas propostas de projetos de lei estabelece uma espécie de curto-circuito entre os especialistas (os deputados) e as pessoas comuns por meio dos fóruns no site, visto que seus participantes não apenas estão lá (no fórum) assistindo silenciosamente ao que está acontecendo, mas estão, sobretudo, interpretando, avaliando e até propondo alternativas para as questôes em jogo.

Assim, se o uso dos fóruns na internet possibilita a participação aberta na esfera pública por meio de posicionamentos discursivos dos usuários participantes (não institucionais), que muitas das vezes são dissonantes em relação ao discurso institucional dominante, então podemos pensar, ainda 
que de forma incipiente, que é possível, nos termos de Rancière, causar uma desordem política na ordem policial, desordem essa fruto de disputa e desacordo, na tentativa de reconhecimento de existência política. É nesse sentido que podemos, falar em "subjetivação política" por meio da Web 2.0, em que aqueles que não têm a sua parte reconhecida na ordem social (os sans-part), os participantes desses fóruns virtuais, reivindicam sua existência como sujeitos políticos na esfera pública.

\section{CONSIDERAÇÕES FINAIS}

Buscamos neste artigo mostrar como o uso da internet, mais especificamente de fóruns institucionais on-line, potencializa práticas discursivas que se coadunam com uma concepção alternativa de política, proposta por Rancière. Para tanto, partimos das noções do autor de "partilha do sensível", "dissenso" e "subjetivação política" para construir um referencial teórico que nos apontasse que a mesma relação hierárquica estabelecida entre aqueles que possuem visibilidade e os que não possuem, dentro de um processo institucionalmente ordenador que aloca indivíduos em lugares particulares ("partilha do sensível"), sustenta também o potencial para a sua própria dissolução ("dissenso"), o que significa que há sempre a possibilidade de participação política daqueles não institucionalmente autorizados ("subjetivação política”).

Assim, pensando empiricamente no nosso objeto de estudo, podemos dizer que os fóruns do Portal da Câmara dos Deputados Federais aqui mostrados, embora sejam, em princípio, considerados ambientes da internet institucionalmente fechados e controlados, possibilitam a criação de espaços de movimentos políticos pelos usuários do portal. Assim, podemos dizer que os discursos produzidos em tais fóruns se constituem como práticas sociais por meio das quais estamos, a todo momento, (re)construindo significados, e isso é feito com base nas posições que ocupamos nas interaçôes sociais das quais participamos (DAVIES; HARRÉ, 1990).

Portanto, podemos afirmar que as práticas discursivas interacionais realizadas por meio dos fóruns analisados tanto apontam lugares institucionais hierarquizados, marcados pela diferenciação entre as vozes dos deputados e dos demais participantes, como também provocam dissensos em meio a uma 
multiplicidade de vozes, que abrem a possibilidade para aqueles considerados como participantes não legítimos na comunidade política dominante de um espaço público de discussão e participação política via produção escrita.

Pudemos notar que a participação política dos sujeitos envolvidos se constitui por meio de controvérsias sociotécnicas coletivas. Estas permitem que as pessoas comuns entrem em conteúdos técnicos relativos à construção de projetos de lei a fim de propor soluções, o que pode levar seus responsáveis (deputados federais) a redefinirem seus projetos em função de novas questões que eles, até então, não haviam considerado. Logo, é possível afirmar que a dinâmica de interação nos fóruns virtuais do Portal, de fato, possibilita aos envolvidos ouvir outras pessoas, responder claramente a seus argumentos e até formular contrapropostas.

Notamos, outrossim, que, em vez de debatarem assuntos através de porta-vozes ou representantes oficiais (no caso, através de outros deputados federais, por exemplo), os atores envolvidos nos fóruns são os próprios representantes de si mesmos, ou melhor, das ideias que defendem por meio de suas práticas discursivas. Com efeito, a relativa equalização do "direito de falar", a oportunidade que todos os participantes têm de argumentar por sua própria conta e questionar as justificações dos parlamentares, transforma, pelo menos por algum tempo, a hierarquia (assimetria) comum que há entre eles, o que, em última instância, contribui para modificar as próprias identidades dos participantes. Nesse sentido, essa prática de debate nos fóruns dialoga com o conceito de Rancière de "subjetivação política", pois sempre envolve um questionamento do "quem pode fazer o que" na ordem social, por isso nunca se constitui por meio de uma afirmação de identidade (no seu sentido estrito) e sempre envolve um "estar junto", na medida em que estamos sempre no entremeio (entre nomes, identidades, culturas, etc.). Em outras palavras, a subjetivação política envolve uma transformação das identidades dadas, ou seja, trata-se muito menos da afirmação de uma determinada identidade (préformada), mas da recusa de uma identidade imposta pela ordem policial.

Com efeito, a redefinição das identidades abre o caminho para compromissos e alianças, que contribuem para a formação de redes de atores compartilhando um projeto comum, e para a emergência de coalisões de "projetos" que, em contrapartida, talvez jamais viessem a existir. Essas reconfiguraçóes de identidades, proximidades e alianças por meio das interações nesses fóruns, em última análise, possibilitam, por meio de suas práticas 
discursivas, a superação dos papéis de "cidadão comum" e de "representantes legítimos". Assim, o que pode estar em jogo para os atores não é apenas o direto de se expressar ou de trocar ideias, mas o de (re)construí-las.

Com tudo o que foi dito aqui, embora a própria discussão mostrada possa levar ao contrário, pensamos que talvez não possamos ainda chamar a atuação política dos usuários envolvidos neste trabalho de uma participação política "na sua versão forte". Os críticos, por exemplo, poderiam, com razão, dizer que o número de pessoas que participam desses tipos de fóruns virtuais é muito pequeno e, por isso, estes ainda estariam longe do acesso popular. No entanto, pensamos que os fóruns on-line de cunho político, como os mostrados aqui, mesmo que ainda não sejam usados pela maioria das pessoas, podem ter função propedêutica de participação política, isto é, podem ser vistos como laboratórios para ensaiar mudanças políticas mais amplas (ou, nos termos de Rancière, subjetivação política), por meio do desejo de debate público; uma demanda para que grupos que são ignorados, excluídos e, em geral, reduzidos ao silêncio, ou cuja voz é desqualificada, tenham o direito de ser ouvidos.

\section{NOTAS}

1 "Système d'évidences sensibles qui donne à voir en même temps l'existence d'un commun et les découpages qui y définissent les places et les parts respectives. Un partage du sensible fixe donc en même temps un commun partagé et des parts exclusives. Cette répartition des parts et des places se fonde sur un partage des espaces, des temps et des formes d'activité qui détermine la manière même dont un commun se prête à participation et dont les uns et les autres ont part à ce partage".

2 "Politics is generally seen as the set of procedures whereby the aggregation and consent of collectivities is achieved, the organization of powers, the distribution of places and roles, and the systems for legitimizing this distribution. I propose to give this system of distribution and legitimization another name. I propose to call it the Police".

3 "The police is essentially the law, generally implicit, that defines a party's share or lack of it. But to define this, you must first define the configuration of the perceptible in which one or the other is inscribed. The police is thus first an order of bodies that defines the allocation of ways of doing, ways of being, and ways of saying, and sees those bodies are assigned by the name to a particular place and task; it is an order of the visible and the sayable that sees that a particular activity is visible and another is not, that this speech is understood as discourse and another as noise". 
4 "Political activity is whatever shifts a body from the place assigned to it or changes a place's destination. [...] It is always a mode of expression that undoes the perceptible divisions of the police order by implementing a basically heterogeneous assumption, that of a part of those who have no part, an assumption that, at the end of the day, itself demonstrates the sheer contingency of the order, the equality of any speaking being with any other speaking being. Politics occurs when there is a place and a way for two heterogeneous processes to meet".

5 "Politics is a matter of subjects, or, rather, modes of subjectification. By subjectification I mean the production through a series of actions of a body and a capacity for enunciation not previously identifiable within a given field of experience, whose identification is thus part of the reconfiguration of the field of experience. [...]Political subjectification produces a multiple that was not given in the police constitution of the community, a multiple whose count poses itself as contradictory in terms of police logic. [...] A mode of subjectification does not create subjects ex nihilo; it creates them by transforming identities defined in the natural order of the allocation of functions and places into instances of experience of a dispute".

${ }^{6}$ A esse respeito, ver http://www.dn.pt/inicio/globo/interior.aspx?content_ $\mathrm{id}=1773616 \&$ seccao=Europa. Acesso em 21 de junho de 2011.

${ }^{7}$ Devemos também chamar a atenção para as intensas manifestações populares que aconteceram em junho deste ano no Brasil, incitadas por meio de redes sociais na internet, e que levaram para as ruas de diversas cidades brasileiras mais de um milhão de pessoas, cujas reinvindicaçôes se estendiam desde a redução das tarifas no transporte público a assuntos mais gerais como fim da corrupção e melhorias na educação e na saúde.

${ }^{8}$ Disponível em: http://edemocracia.camara.gov.br/.

${ }^{9}$ Uma das falhas do portal é que muitas comunidades virtuais não disponibilizam a opção "wikilegis" para seus usuários, tampouco explicitam as razões para a não disponibilização da ferramenta.

${ }^{10}$ Disponível em: http://edemocracia.camara.gov.br/web/politica-sobre-drogas/inicio.

${ }^{11}$ Equipe que organiza as formas de interação no Portal E-democracia.

${ }^{12}$ Embora todas as comunidades do Portal E-democracia sejam abertas, por questôes éticas, optamos por não exibir os perfis (identificação e fotos) dos usuários participantes envolvidos nos fóruns (os perfis foram ocultados por meio de retângulos). $\mathrm{O}$ único perfil que será exibido é o da Deputada Iracema Portella, visto que se trata de uma representante pública. 
${ }^{13}$ Disponível:http://www2.camara.gov.br/atividade-legislativa/comissoes/comissoestemporarias/especiais/54a-legislatura/politicas-publicas-de-combate-as-drogas/ arquivos/relatorio-do-dep.-givaldo-carimbao.

14 "politics is an activity which not only interrupts the police order but reconfigures it for the better".

\section{REFERÊNCIAS}

CASTELLS, M. A sociedade em rede. A era da informação: economia, sociedade e cultura. V 1, 8. ed. São Paulo: Paz e Terra, 2005.

DAVIES, B. \& HARRÉ, R. Positioning: The Discursive Production of Selves. Journal for the Theory of Social Behaviour. Vol. 20, p. 43-63, 1990.

FABRÍCIO, B. F. Implementação de mudanças no contexto educacional: discursos, identidades e narrativas em ação. Tese (Doutorado em Estudos da linguagem) - PUCRJ, 2002.

FOUCAULT, M. Les Techiniques de soi. In Foucault, M. Dits et écrits. Paris: Gallimard, vol.IV, 1998.

GOFFMAN, E. Interaction ritual: Essays on face-to-face behavior. New York: Pantheon, 1981.

KNOBEL, M, LANKSHEAR, C. A new literacies sampler. New York: Peter Lang Publishing, Inc., 2007.

KRESS, G. Multimodality: A social semiotic approach to contemporary communication. London; New York: Routledge, 2010.

LÉVY, P. Cibercultura. Tradução de Carlos Irineu da Costa. São Paulo: Editora 34, 1999.

. Ciberdemocracia. Lisboa: Instituto Piaget. 2003.

O'REILLY, T. What is Web 2.0?: Design patterns and business models for the next generation of software. 2005. Disponível em: http://oreillynet.com/pub/a/oreilly/tim/ news/2005/09/30/what-is-web-20.html. Acesso em: 4 abr. 2008.

RANCIÈRE, J. Disagreement: Politics and philosophy. Translation: J. Rose. Minneapolis: University of Minnesota Press, 1999.

. Ten Theses on Polities', Theory \& Event. Thesis 1. 5, 3. 2001. Disponível em: http://www.after1968.org/app/webroot/uploads/RanciereTHESESONPOLITICS. pdf. Acesso em: 11 ago. 2011.

. The Politics of Aesthetics: The Distribution of the Sensible. Tradução: Gabriel Rockhill, with an Afterword by Slavoj Zizek. London: Continuum, 2004. 
Le partage du sensible. Entretien avec Jacques Rancière. Multitudes: Revue Politique, Artistique e philosophique, 2007. Disponível em: http://multitudes.samizdat. net/Le-partage-du-sensible. Acesso em: 11 dez. 2011.

VAN LANGENHOVE, L. \& HARRÉ, R. Introducing Positioning Theory. In: Harré, R. \& Van Langenhove, L. (Eds.). Positioning Theory. Oxford: Blackwell, 1999.

Submissão do artigo: 30/09/2013

Aprovação do artigo: 08/12/2013 